\title{
ALUMINIUM ODER GUSSEISEN?
}

Liebe Leserin, lieber Leser,

bei Pkw-Motoren war in den vergangenen Jahrzehnten eine eindeutige Entwicklung hin zu Zylinderkurbelgehäusen aus Aluminium zu verzeichnen. Angefangen bei den Ottomotoren, etablierte sich der Werkstoff letztlich auch bei Dieselmotoren. Experten schätzen, dass aktuell mehr als die Hälfte aller Zylinderkurbelgehäuse für Pkw-Motoren aus Aluminium gefertigt werden. Da ein Zylinderkurbelgehäuse bis zu $25 \%$ des Gesamtgewichts eines typischen Motors ausmacht, bietet sich ein großes Potenzial zum Leichtbau.

Bis vor Kurzem galt daher: Wer einen modernen Pkw-Motor entwickeln wollte, kam an Aluminium oder gar dem noch leichteren Magnesium kaum vorbei. Das könnte sich künftig wieder ändern, wenn immer mehr Motoren mit starkem Downsizing auf den Markt kommen.

Denn der Gewichtsnachteil von Gusseisen zu Aluminium ist vom Hubraum und den Motorabmessungen abhängig, bei kleinen Motoren ist der Unterschied eher gering. So fertigt Ford den Zylinderblock des hochgelobten 1,0-1-DreizylinderEcoBoost-Motors aus Grauguss. Das gibt dem Hersteller nach eigenen Angaben die Möglichkeit, den Motor extrem kompakt auszulegen. Dadurch konnte auf Ausgleichswellen verzichtet werden, sodass Ford beim Gesamtmotor durch die Werkstoffwahl sogar Gewicht einspart.

Offenbar gilt dies nicht nur für Dreizylinder. Auch Opel rüstet einen der Hoffnungsträger im Programm, den kürzlich vorgestellten 1,6-1-Vierzylinder-Ottomotor, mit einem Grauguss-Zylindergehäuse aus, kombiniert mit einer Aluminiumgrundplatte. Bei diesem Downsizing- aggregat argumentiert der Hersteller ebenfalls mit einer kompakteren Bauweise und einem besseren NVH-Verhalten durch die Graugussstruktur. Ob das ein genereller Trend zurück zum Gusseisen wird, bleibt abzuwarten. Denn auch für Aluminium sprechen noch gute Gründe, wie Opel an anderer Stelle zeigt: Beim neuen 1,6-1-Dieselmotor wurde - erstmals übrigens in der Dieselmotoren-Fertigung bei Opel - Aluminium anstelle von Gusseisen für den gesamten Motorblock verwendet. Damit konnte Opel in Summe 20 kg Gewicht einsparen und das selbstgesteckte Ziel erreichen, den Klassenmaßstab beim Verhältnis von Leistung zu Gewicht zu setzen. Wie so häufig in der Konstruktion scheint es also auch hier keine einfache Patentlösung zu geben. Die Frage ist vielmehr, wie die Anforderungen am besten zu erfüllen sind.

Herzlichst, Ihr

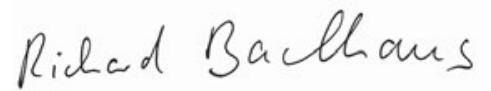

RICHARD BACKHAUS,

Stellvertretender Chefredakteur Wiesbaden, 13. April 2013

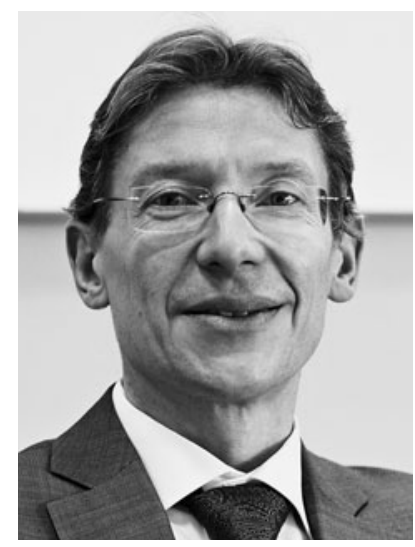

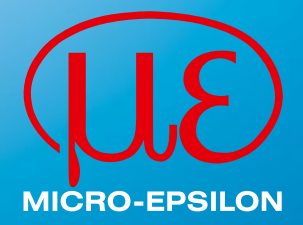

MICRO-EPSILON

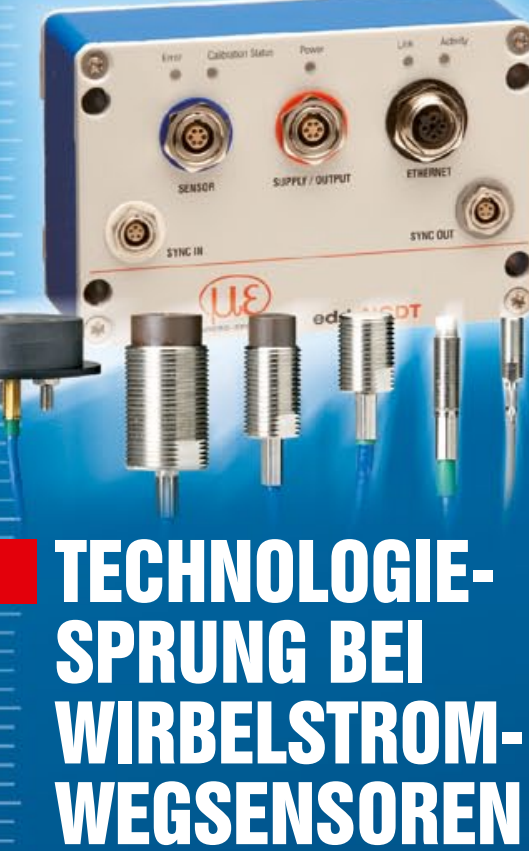

Die neuen Sensorsysteme eddyNCDT 3100 bieten mehr Präzision \& höheren Bedienkomfort durch:

- Intelligente Kombination von Analogund Digitaltechnik

- Sensoren tauschbar ohne Neuabgleich

- Webbrowser basierte Bedienung über PC

- Ethernet-Schnittstelle

- Messbereiche 0,5 mm - $15 \mathrm{~mm}$

- Sensoren IP67 mit hochflexiblem Kabel

- Controller (Metallgehäuse IP65) für Hutschienen und Schraubmontage

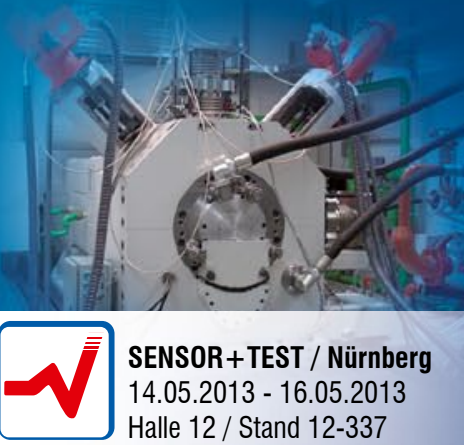

www.micro-epsilon.de

MICRO-EPSILON Messtechnik

94496 Ortenburg - Tel. 0 85 42/168-0

info@micro-epsilon.de 